\title{
Evaluating cemented paste backfill plug strength and the potential for continuous pouring ${ }^{1}$
}

\author{
Murray Grabinsky \\ University of Toronto, Toronto, Ontario, Canada \\ Ben Thompson \\ RockEngineering Inc., Kingston, Ontario, Canada \\ Will Bawden \\ Mine Design Technologies, Kingston, Ontario, Canada
}

\begin{abstract}
Currently there appears to be no rational method of defining plug strength in a typical "plug and cure" backfilling strategy, which is a significant problem when many engineered backfill containment structures include assumptions that the backfill plug isolates the structure from pressure applied by the subsequent "main" backfill volume. The proposed method for plug strength determination is presented as an analytical solution supported by numerical modelling and case study data. By extension, this method enables definition of required backfill strength for continuous backfilling.
\end{abstract}

Keywords: Cemented Paste Backfill, Continuous Pouring, Plug Strength

\section{INTRODUCTION}

Deep and high stress mining requires fast and effective backfilling to support the exposed sidewalls surrounding an open stope, and thereby limit the stress concentrations that would otherwise build up and potentially lead to dangerous rockbursting conditions. For relatively tall open stopes (e.g., longhole and Alimak stoping methods) a containment structure, i.e. barricade or rock berm is constructed in the undercut access to contain the initially placed backfill "plug". The plug extends a few meters above the undercut's brow and must cure (gain strength) before starting the overlying "main" backfilling. The purpose of the plug is to isolate the barricade from induced stresses applied by this main backfill volume. The ideal situation is to engineer backfilling such that the plug will cure as it is being placed and will have sufficiently gained strength, on average, that backfilling can switch from plug to main backfills without stopping for a cure period. However, backfill plugs are typically placed and allowed to cure for between 24 hours and seven days prior to the onset of backfilling the main volume such that an adequate plug strength is achieved. There are exceptions, in which mines have optimized this process through understanding of barricade capacity (which requires an engineered barricade design and application of adequate quality control) and routine measurement of pressures applied by the backfill on the barricade, such that continuous pouring can be

\footnotetext{
${ }^{1}$ This is an abbreviated version of a manuscript submitted for peer review; the expected final version contains additional background information, full analytical solution development, and additional case studies.
}

DOI: $10.1201 / 9781003205906-13$ 
safely achieved (e.g., Li et al., 2014). Continuous pouring provided potentially significant savings through reduced stope cycle times. It should be noted that the potentially fatal consequences of barricade failure, in terms of a high energy inrush of fluid backfill, justifies an extremely cautious approach to backfilling. Cemented Paste Backfill (CPB) is the only method that offers the potential for continuous backfilling; unlike $\mathrm{CPB}$, hydraulic backfills require drainage periods during which no filling occurs to ensure safe backfilling.

Previously, the design of backfill containment structures has been considered by various authors, with most recently Oke et al. (2018) demonstrating that barricades must be considered as a system along with rock abutments as significant reduction in capacity can be expected in soft rock conditions. Design or definition of adequate plug strength should also be included in the backfill containment system design, as frequently the backfill barricade assumes a design load applied by the plug height of fluid backfill. This implies the plug will isolate the barricade from the effects of the "main" pour.

To our knowledge, there is limited published information that justifies plug strength requirements. For instance, it has been suggested that the backfill in the plug must generally achieve an Unconfined Compressive Strength (UCS) of $150 \mathrm{kPa}$ (Henderson et al., 2005), however this recommendation is offered without justification in terms of explanation or engineering foundation. Clearly, the plug must have strength such that the backfill is liquefaction resistant, and it is frequently considered based on empirical data that $100 \mathrm{kPa}$ constitutes an acceptable minimum strength to achieve this. A discussion of liquefaction resistance of paste is outside the scope of this discussion; readers are referred to Been et al. (2002), le Roux et al. (2005), Shahsavari et al. (2014). It is worth noting however, that liquefaction of paste has not to the authors knowledge occurred to cause barricade failure events. An important clarification should be made that barricade failures involving fluid paste do not constitute liquefaction events if the poured paste never transitioned from a fluid to a solid state.

In order to develop a rational engineering approach to backfill plug design it is first necessary to anticipate the potential failure mode. Forensic analyses of backfill and barricade failures (e.g., Grice, 1998; Torlach, 2000; Mangan, 2001; Grice, 2001; Yumlu and Guresci, 2007; Revel and Sainsbury, 2007) have identified some causal mechanisms (e.g., internal erosion and piping in hydraulic fills, rockfalls and groundwater intrusion in fresh fills, quality control issues with construction, over-pressurization in blind fills) but the actual backfill failure mechanism behind the barricade cannot be determined because the ensuing outrush of failed material erodes the original failure surfaces within the backfill plug.

The purpose of this paper is therefore to rationalize the potential failure mechanism occurring through the plug backfill in order to determine the limiting required plug strength to resist such failure. The original motivation for conducting this analysis was to determine adequate plug strength from a consulting perspective in order to provide a complete backfill barricade design package. Given the extent of efforts to produce engineered barricade designs, it would seem curious that determination of adequate plug strength typically receives relatively scant attention. In addition to the definition of plug strength for a plug pour, cure and main pour strategy, the analysis presented would logically extend to defining the plug backfill strength for which no plug cure is required - i.e., a continuous pour. While this design approach has not been verified in new field trials, a suggested method (subject to site specific safeguards) is provided based on case histories.

Two published case studies are used to motivate the plug strength analysis and identify critical design assumptions. A numerical analysis is carried out from which the failure mechanism is identified. An analytical solution for this mechanism is developed and compared with the numerical analyses. A general design approach is then described and applied to the back-analyses of the case studies. A critical limiting assumption, based on the case studies, is that the plug backfill is in a state of zero effective stress and therefore only material cohesion can be mobilized. Some consideration is therefore given to other mines where early effective stress development may occur, and how the suggested design approach would have to be adapted for these design scenarios. 


\section{CASE STUDIES}

Two of the most thoroughly documented mine backfill in situ pressure case studies come from Cayeli mine (Thompson et al., 2012; this is an Editor's Choice article for "particularly high caliber and topical importance" and is freely available from the Canadian Geotechnical Journal web site at http://www.nrcresearchpress.com/doi/abs/10.1139/t2012-040). The first case study, stope 715, involved high barricade pressures which necessitated stopping the pour for a plug cure period. The second case study, stope 685, featured sufficiently low barricade pressures that a successful continuously poured stope was achieved. These are therefore useful bounding case studies for validating potential design methods against actual field conditions. Both stopes used flat reinforced shotcrete barricades with limited setback from the undercut's brow. The main differences were in the backfill rise rates, backfill binder contents and in the types of tailings used in the backfill mix designs.

These backfills were monitored using clusters of total earth pressure cells (TEPCs) and piezometers attached to cages for in-stope installation (Figure 1a). Several cages were placed between the barricade and the middle of the stope just above floor level, as well as suspended on cables up the stope's height (Figure 1b). Additional TEPCs and piezometers were attached to the barricade's fill side, and the displacements were measured on the barricade's free side. The mine's experience was that a barricade pressure limit of $100 \mathrm{kPa}$ was the maximum, at which point backfilling should be halted.

Figure 2 shows the stress monitoring results for the two case studies. For each case, two cages are considered, both location in the approximate center of the stopes. Cages 3 are located within the plug while cages 5 are located within the main fills. The binder content within the 685 plug was $8.5 \%$, with a $6.5 \%$ binder content deployed above $9 \mathrm{~m}$ height in the $18.6 \mathrm{~m}$ high stope. Paste reached the $6.4 \mathrm{~m}$ elevation after 24 hours of backfilling and the measured pressures were hydrostatic (i.e., vertical as well as the two horizontal total earth pressures are equal to pore water pressure) and so the paste was in a zero-effective-stress state at the Cage 3 location (at $2 \mathrm{~m}$ elevation) until the plug height was achieved. For reference (but

a)

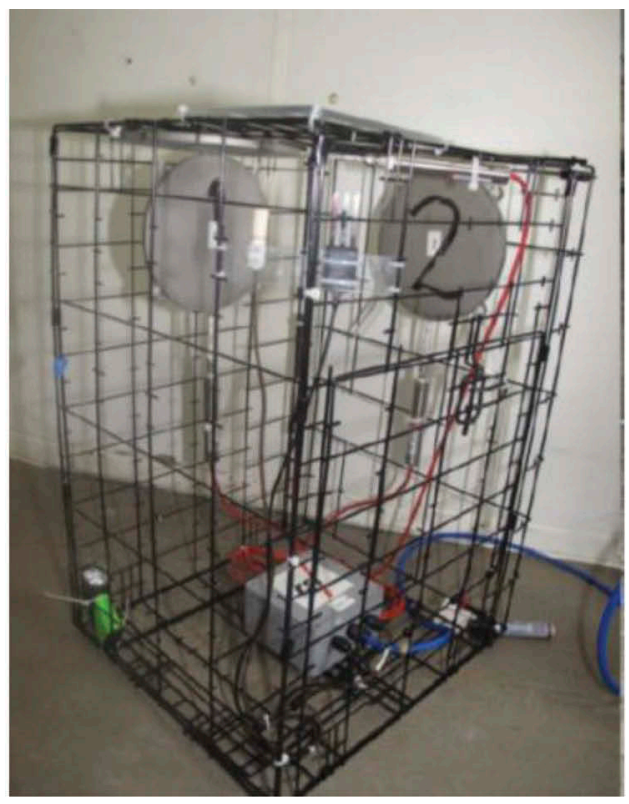

b)

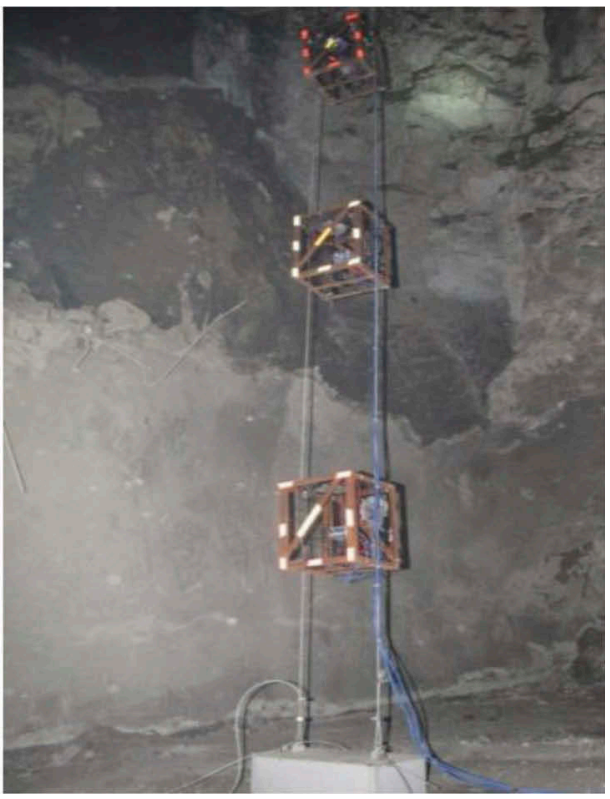

Figure 1. a) A cage with instruments for monitoring total earth pressures and water pressures; b) cage installations in a stope. 

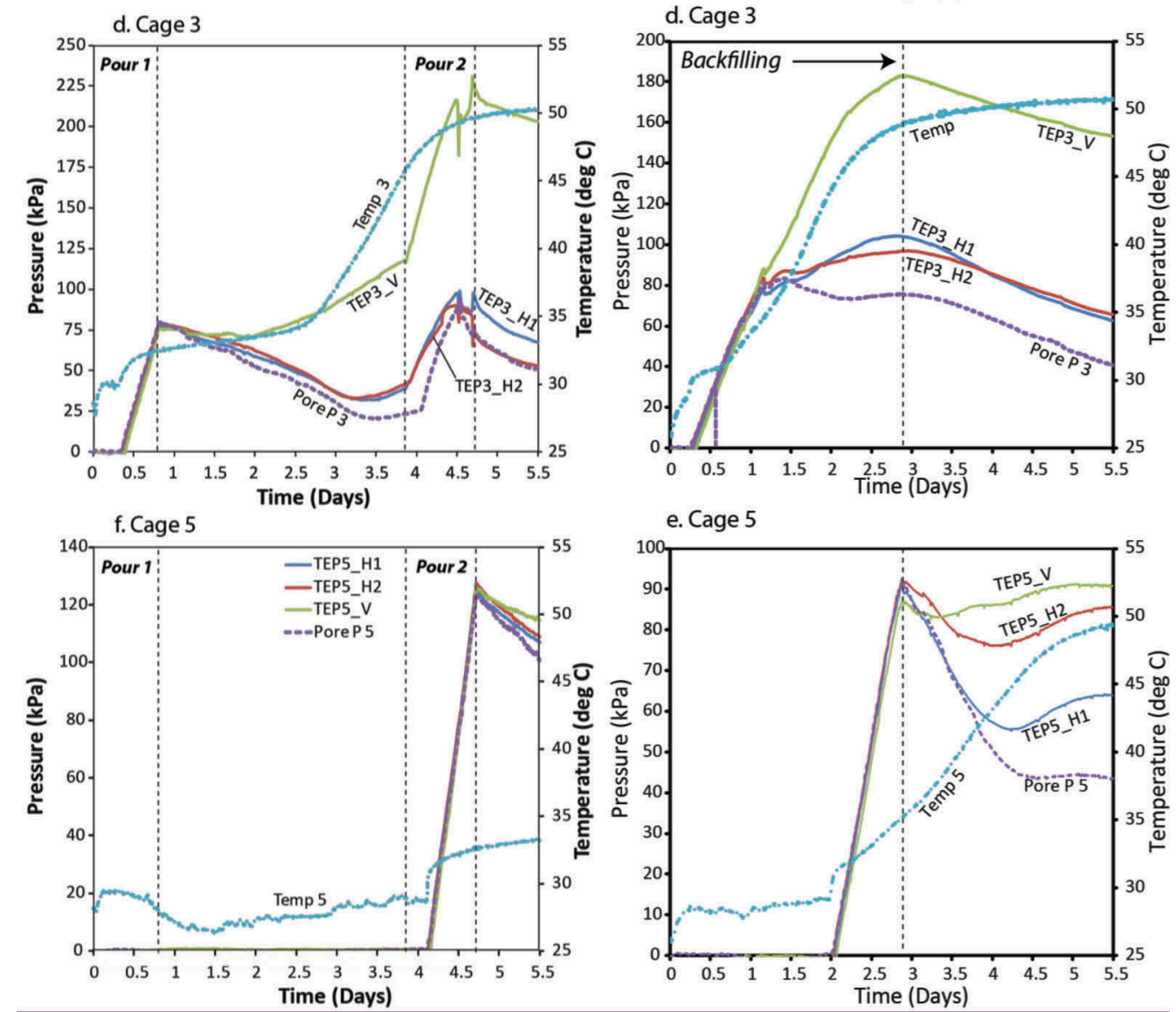

e. Cage 5

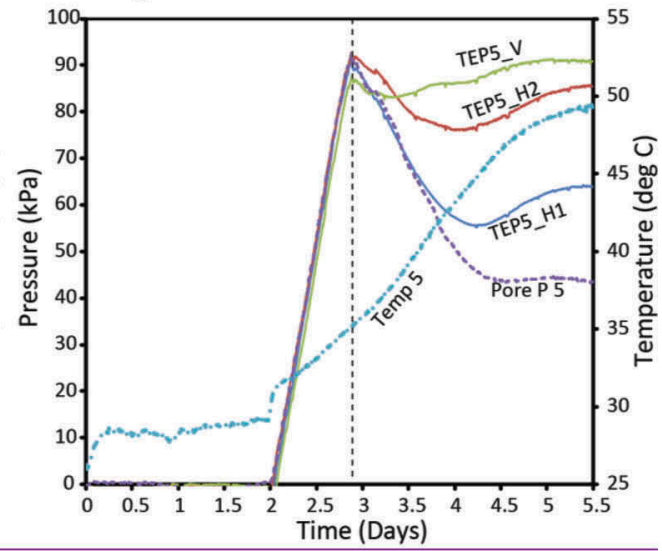

a) 715 staged pour (high barricade pressure)

b) 685 continuous pour (safe condition)

Figure 2. Cayeli stress monitoring results (cages 3 are in plug; cages 5 are above plug), after Thompson et al. 2012.

not shown), non-hydrostatic loading was measured near the barricade 14 hours after paste reached the Cage 3 location. Barricade pressures did not increase linearly, and indeed peaked at $40 \mathrm{kPa}$ (after 0.6 days of backfilling) and reduced before the plug pour was complete.

The plug height $(6.4 \mathrm{~m})$ for the 715 Stope was achieved within 20 hours of backfilling, during which time zero effective stress was measured throughout its filling. Unlike the 685 stope, 715 barricade pressures (not shown) increased linearly throughout the duration of the plug pour. The 715 stope featured $6.5 \%$ binder throughout; and indeed featured backfill made using a separate tailings stream to the 685 stope.

That there was significant difference in the rate of strength gain in the backfill for the respective plug volumes is indicated by temperature measurements, with the exothermic cement hydration responsible for temperature increase for 685 being very strong throughout the entire pour, while for 715 there is a slow temperature increase until a notable acceleration about $2 \frac{1}{2}$ days into the pour. Given that the backfill is a frictional material, zero effective stress represents a worse-case design condition in that it implies only the backfill cohesion can be relied upon.

For each stope, cages 5 are located within the main pours. In both cases the backfills undergo zero effective stress throughout the main pour period (i.e. $>20$ hours of hydrostatic 
loading was measured within the 685 stope "main" volume). This implies a fluid loading condition was applied on the plug's top surface.

The 715 pour was stopped about 0.8 days into backfilling when the pressure cell located at about $1 / 3$ barricade height reached the $100 \mathrm{kPa}$ assumed barricade pressure limit. The barricade at this point was extensively cracked and leaking backfill water. Sophisticated reinforced concrete numerical analysis codes from the University of Toronto's structural analysis research group were used to back-analyze the barricade's pressure-displacement response and cracking patterns. These results indicated that the barricade was loaded close to its ultimate capacity (Grabinsky et al., 2014), and as such the plug cure backfill strategy was a requirement for safe backfilling.

In contrast, the 685 pour exhibited less pressure at the barricade than at the cage 3 location, suggesting strength gain of the backfill at the brow location backfill (regardless of the zero effective stress state measured at the center stope Cage 3 location) which allowed a safe continuous pour with no obvious signs of barricade distress and smaller barricade displacements. Readers are referred to Thompson et al. (2012) for fuller discussion of these results.

The conclusions arising from these case studies specific to the plug strength analysis are therefore: 1) as a worst-case scenario the plug can exist in a state of zero effective stress and therefore only cohesion will contribute to plug strength; and 2) the subsequent main backfill pour can be assumed to exert a fluid pressure on the plug's top surface. The next section seeks to identify the potential failure mechanism through the backfill plug that could arise under these circumstances.

\section{MODELED FAILURE MECHANISM AND ANALYTIC SOLUTION}

As a starting point for analysis the undercut is assumed to be square in cross-section and the plug is assumed to extend only to the brow height. The backfill is assumed to have constant cohesion and unit weight. A total stress is applied to the plug's top surface to represent the fluid loading arising from the main pour.

Analyses of this type were carried out using Flac3D which showed a failure mechanism developing with similarities to the Prandtl wedge solution for failure under a footing on undrained clay (Figure 3). The lateral extent is essentially limited by the undercut's sidewalls. A triangular wedge forms at the backfill's surface and mobilizes a radial fan (with a $22.5^{\circ}$ subtended angle) which in turn pushes on the block of backfill within the undercut. The analyses were subsequently extended to include the plug portion above the brow, and also to consider a linear distribution of cohesion from zero at the plug's top surface in order to represent the plug's varying strength properties. Based on these analyses the equation for limiting plug stability can be written

$$
\mathrm{q}+\gamma(\mathrm{d}+0.55 \mathrm{H})=\mathrm{c}(3+4 \mathrm{~d} / \mathrm{H}+4 \mathrm{~L} / \mathrm{H})
$$

The fluid loading q arising from the main backfill is simply the backfill's unit weight multiplied by the height of main backfill above the plug at any given time. The cohesion $\mathrm{c}$ is the average cohesion at the undercut's mid-height. The above solution does not incorporate barricade strength: it assumes the barricade is designed for initial plug fluid pressures only, and that the effect of the main pour should not be transmitted to the barricade. It is considered that this solution constitutes the primary contribution of this paper in terms of a means of a rationally engineered determination of adequate plug strength for backfill system design. In order to achieve this for a mine with no calculated value of $c$, the relationship $c=1 / 4$ UCS has been used, and appropriate QA/QC and safety factor assessments are required.

Another contribution of this paper is to extend this analysis to provide framework showing how the minimum plug strength to allow a continuous pour can be determined. To this end, the case study data is assessed and back-analysis is conducted. 

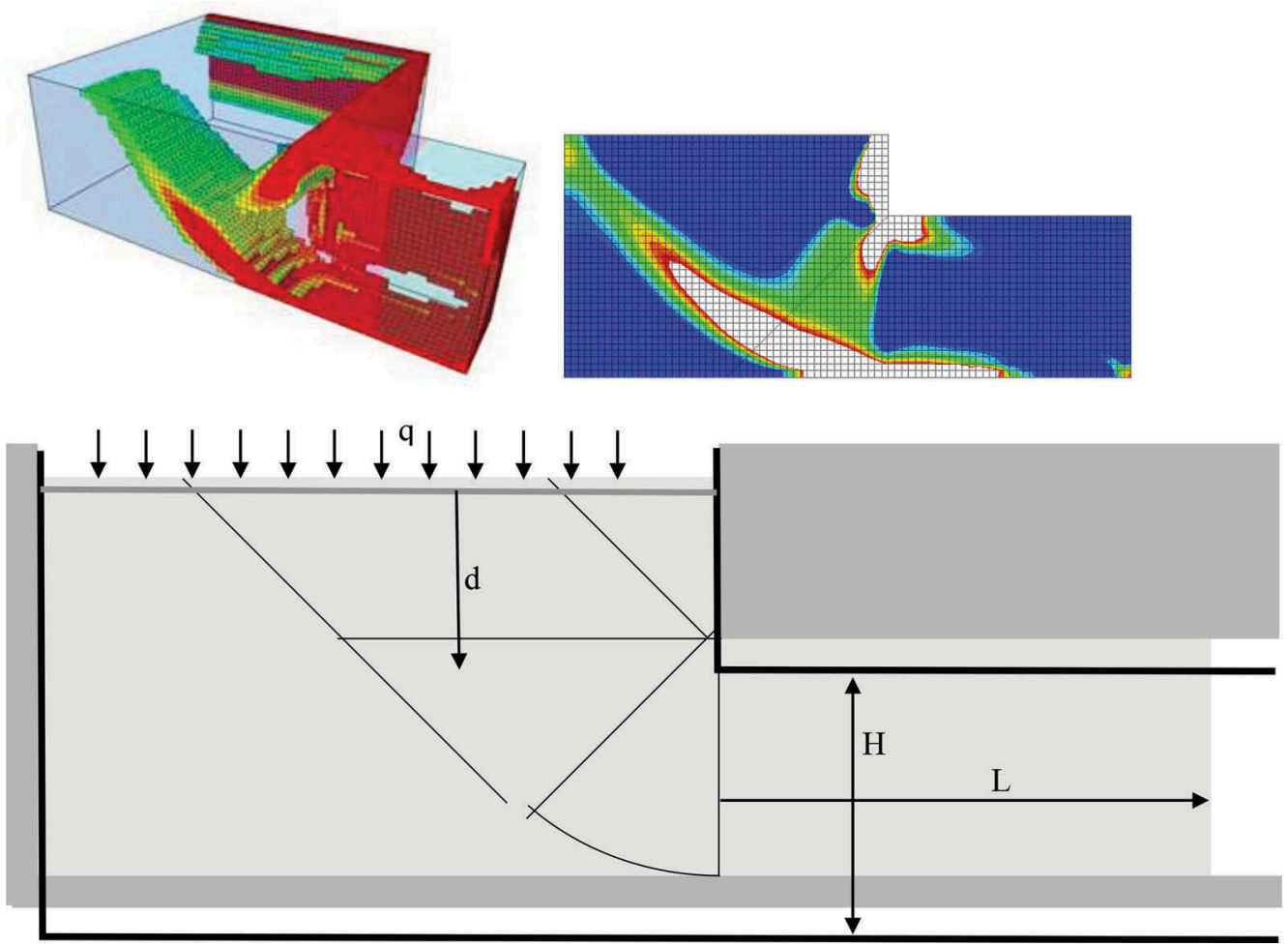

Figure 3. Numerical analysis showing plug failure mechanism (top) and analogy to Prandtl mechanism (bottom).

For a continuous pour analysis it is important to have comprehensive data for the development of cohesion with time during the entire filling process. Veenstra (2013) showed that this could be achieved using direct shear tests. Figure 4 shows results for plug CPBs from four mines, with cohesion determined starting at 4 hours (after paste mixing) up to about 14 days. For the two Cayeli case studies, stope 715 uses clastic tailings with $6.5 \%$ binder, while stope 685 uses non-clastic tailings with $8.5 \%$ binder plug and $6.5 \%$ binder main volume. For the two stopes, the early plug strength developments are dramatically different: cohesion for the stope 715 clastic tailings only increases significantly after about $2 \frac{1}{2}$ days (60 hours), which roughly corresponds to when the temperature dramatically increases in the stope.

The delayed strength development for the 715 backfill plug is likely responsible for the relatively high pressure barricade conditions discussed previously. It should also be noted that every CPB mix design exhibits unique cohesion development with time, due to the different curing stages associated with each combination of tailings mineralogy and binder chemistry. A plug strength design procedure is suggested next, and then applied to the back-analysis of Cayeli 715 and 685 stopes.

\section{DESIGN STEPS AND BACK-ANALYSES}

In order to determine plug strength requirements for a specific stope geometry, it is necessary to calculate the imposed fluid backfill head acting on the plug surface and apply Equation 1 and then determine adequate time (based on the specific paste recipe) required for the plug to cure. A rigorous QA/QC process is required to determine adequate plug strength has been achieved based for specific stopes using at minimum, Unconfined Compressive Strength testing and in-situ instrumentation (i.e. to measure barricade pressures). 


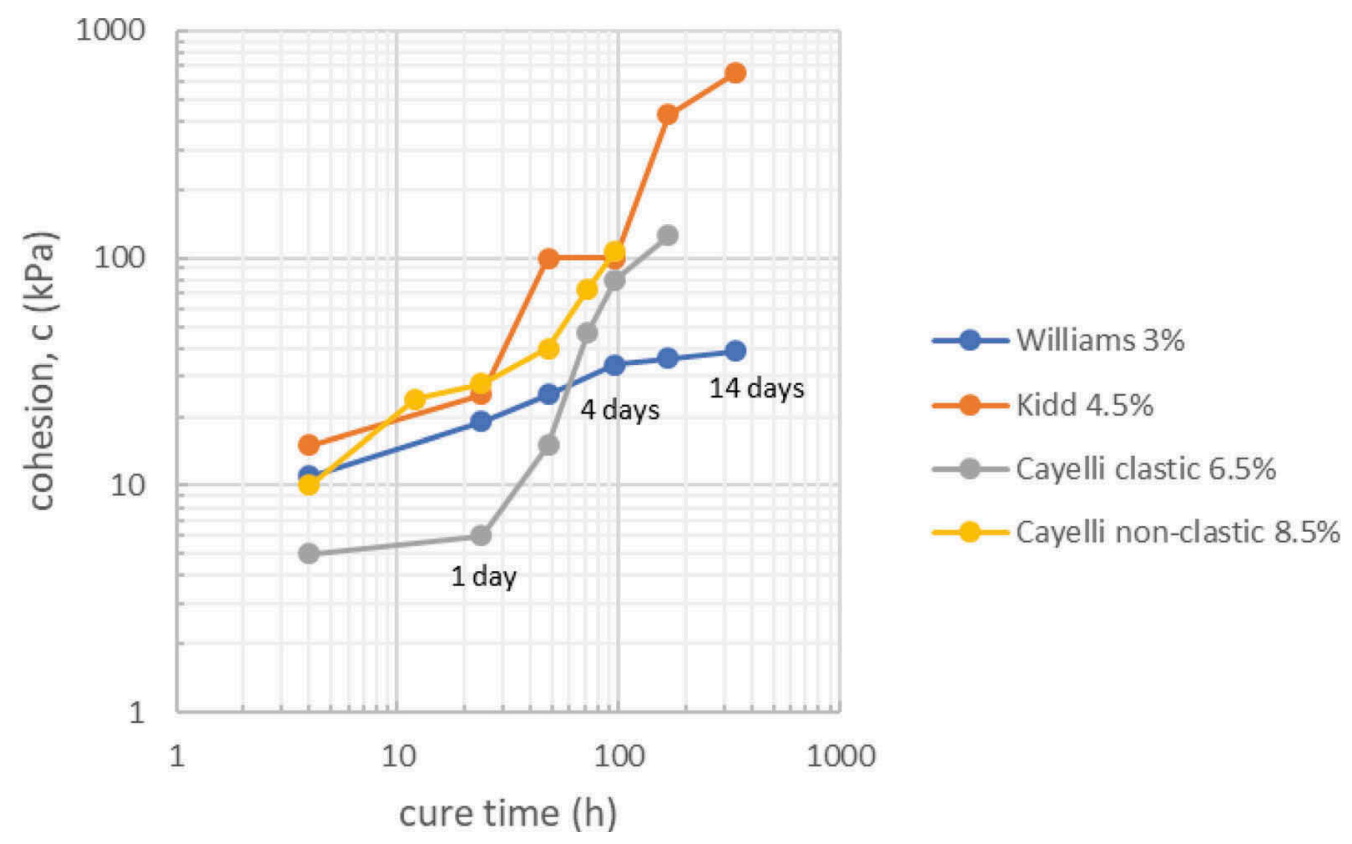

Figure 4. Laboratory determined cohesion development with time (adapted from Veenstra, 2013).

This paper does not attempt to review the complete nature of such a process, and caution is required to ensure safe backfilling practices are maintained. In the following description an idealized process by which an operation could determine plug strength requirements are suggested and indeed, the theoretical possibility of a continuous pour could be assessed. Where applicable, these steps have been used to back-analyze the case study data and calibrate the plug strength determination method presented herein.

The recommended plug strength design steps are:

1. Design the backfill barricade to resist the head of fluid backfill to the full plug height, in case of binder hydration in the plug occurring under a prolonged zero effective stress state (or confirm an existing design satisfies this condition).

2. Determine cohesion as a function of cure time as shown in Figure 4 for the plug paste.

3. Conduct a cavity monitoring survey of the open stope prior to filling. Based on cavity geometry and on the backfill plant's delivery rate, determine the expected fill rise rate(s) (or determine a representative worst-case rise rate for typical stopes).

4. Determine when the backfill will reach barricade mid-height elevation and establish this as the reference time $\left(t_{r e f}\right)$ with respect to a representative average curing time (and therefore cohesion developed) for the backfill plug. If possible, adjust (increase) this time for the mixing time in the backfill plant, the transport time in the pipe distribution network, and the travel time from the deposition point to the final placement location (however, this adjustment is not as important for rapidly hydrating backfills).

5. Determine critical times (with respect to the above-determined reference time) when the paste covers the barricade, when plug filling is complete, when different stages of binder hydration take place, when significant changes in stope geometry (and therefore fill riserates) occur, etc. and calculate the expected backfill cohesion for these reference cure times.

Calculate the plug's ultimate resistance to imposed surcharges using Equation 1 and convert this into an equivalent head of fluid backfill, i.e., $h_{\text {max,eq }}=q / \gamma$. Alternatively, do the same using Equation 2: 


$$
\mathrm{h}_{\text {max }, \text { eq }}=(\mathrm{c} / \gamma)(3+4 \mathrm{~d} / \mathrm{H}+4 \mathrm{~L} / \mathrm{H})-(\mathrm{d}+0.55 \mathrm{H})
$$

7. Consider the result of Step \#6 when the plug fill completes. A negative value means the plug does not have sufficient strength to support its own self-weight and therefore the plug requires additional cure time before the main pour starts.

8. Consider subsequent fill stages. If the calculated $\mathrm{h}_{\text {max,eq }}$ is less than the actual expected main pour height above the plug, $\mathrm{h}_{\mathrm{ac}}$, then the plug needs strengthening through higher binder content and/or longer cure time, or else through pore water pressure dissipation and effective stress development (which implies employing a more sophisticated analysis technique).

Note that if a mining operation implements the above, then the time when backfilling reaches the undercut's mid-height (Step 4) is the time to collect multiple control samples (probably taken at the paste plant) for subsequent strength testing when the plug pour completes (Step 7). If the control samples' strengths satisfy the specified design criterion, then continuous pouring may theoretically proceed; otherwise, starting the main pour must wait until sufficient strength develops in the control samples (and, presumably in the plug backfill). These specific control samples would be in addition to samples collected routinely during the entire pour for more general QA/QC purposes. The following two case studies illustrate the above design steps.

It is emphasized that the above presents a theoretical approach, and any attempt to determine an adequate plug strength, or accelerate backfilling should deploy all means of verification that safe backfilling (i.e. at a minimum, barricade instrumentation) is occuring.

\subsection{Cayeli 715 case study: Plug Cure Required due to High Barricade Pressures}

Cayeli 715 is a long-hole stope approximately $15 \mathrm{~m}$ long, $8.5 \mathrm{~m}$ wide and $15 \mathrm{~m}$ backfilled height, with the barricade constructed very close $(\mathrm{L}=1.8 \mathrm{~m})$ to the brow. The barricade height is $4.5 \mathrm{~m}$ but the brow angles up into the stope with an average height $\mathrm{H}=5.0 \mathrm{~m}$, so that $\mathrm{L} / \mathrm{H}=0.36$. The backfill unit weight is $\gamma=22.4 \mathrm{kN} / \mathrm{m}^{3}$. Based on the backfill plant's delivery rate the average rise rate is expected to be $0.37 \mathrm{~m} / \mathrm{h}$ but more detailed geometry is used to obtain better values for expected elevation with time in this analysis. Table 1 shows the (abbreviated) predicted response and the plug cannot even support its own self-weight. This analysis result is consistent with the observation that the barricade suffered significantly high pressure, and as such verifies the proposed design method for a "poorly performing plug" case. The analysis might seem trivial except for the fact that the 715 pour was eventually completed successfully and so the actual filling strategy requires further investigation. As an aside, this

Table 1. Key backfill times and plug capacities for 715 stope (assuming continuous pour).

\begin{tabular}{|c|c|c|c|c|c|c|c|}
\hline Note & $\begin{array}{l}\text { Pour } \\
\text { time (h) }\end{array}$ & $\begin{array}{l}\text { Fill el. above } \\
\text { floor }(\mathrm{m})\end{array}$ & $\begin{array}{l}\text { Cure } \\
\text { time (h) }\end{array}$ & $\begin{array}{l}\text { Backfill } \\
\text { c (kPa, } \\
\text { Figure 4) }\end{array}$ & $\begin{array}{l}\mathrm{q}_{\max }(\mathrm{kPa}, \\
\text { Eq. 1) }\end{array}$ & $\begin{array}{l}\mathrm{h}_{\mathrm{eq}}(\mathrm{m}, \\
\text { Eq. 2) }\end{array}$ & $\begin{array}{l}\text { Fill el. } \\
\text { above } \\
\mathrm{H}(\mathrm{m})\end{array}$ \\
\hline start & 0 & 0 & $\mathrm{n} / \mathrm{a}$ & $\mathrm{n} / \mathrm{a}$ & $\mathrm{n} / \mathrm{a}$ & $\mathrm{n} / \mathrm{a}$ & $\mathrm{n} / \mathrm{a}$ \\
\hline mid-baricade & $8\left(t_{r e f}\right)$ & 2.2 & 0 & 0 & $\mathrm{n} / \mathrm{a}$ & $\mathrm{n} / \mathrm{a}$ & $\mathrm{n} / \mathrm{a}$ \\
\hline initial plugset & 12 & 3.3 & 4 & 5 & $\mathrm{n} / \mathrm{a}$ & $\mathrm{n} / \mathrm{a}$ & $\mathrm{n} / \mathrm{a}$ \\
\hline top-barricade & 16 & 4.5 & 8 & 5.2 & $\mathrm{n} / \mathrm{a}$ & $\mathrm{n} / \mathrm{a}$ & $\mathrm{n} / \mathrm{a}$ \\
\hline fill undercut & 17.5 & 5.0 & 9.5 & 5.3 & -38 & $\mathrm{n} / \mathrm{a}$ & 0 \\
\hline top of brow & 19 & 5.6 & 11 & 5.4 & -48 & $\mathrm{n} / \mathrm{a}$ & 0.6 \\
\hline
\end{tabular}


result shows the importance of employing barricade pressure measurements to verify safe backfilling.

In actuality the pour was stopped when the maximum barricade pressure reached close to the threshold value at the completion of the plug height, and as planned, a plug cure period was enforced. This plug cure time resulted in sufficient strength to support the main pour. A similar back-analysis of the actual filling history is presented in tabular form in Table 2, and graphically in Figure 5. The cohesion increased significantly by the time the pour resumed (to $65 \mathrm{kPa}$ ) and at that time could theoretically support an imposed main volume backfill height $12.2 \mathrm{~m}$ which exceeded the required $8.4 \mathrm{~m}$ additional height for the main pour. The main pour therefore continued successfully and by the time it completed the plug had $87 \mathrm{kPa}$ cohesion and could have supported almost double the imposed main backfill height. In fact, with the benefit of hindsight offered by this retrospective analysis, theoretically the main pour could have safely resumed even earlier. Finally, it should be noted that the delayed hydration for this backfill and its impact on early strength development was not fully appreciated at the time of the fieldwork (however, the mine no longer uses this particular mix design).

\subsection{Cayeli 685 case study: Successful continuous pour}

The overall geometry of the 685 stope was slightly larger than the 715 stope, with length $23 \mathrm{~m}$, width $8.5 \mathrm{~m}$ and backfill height up to $17 \mathrm{~m}$. Because of the larger volume, the average backfill rise rate was lower: $0.23 \mathrm{~m} / \mathrm{h}$. The flat barricade was $5.2 \mathrm{~m}$ high and was set back from the brow a distance $\mathrm{L}=2.5 \mathrm{~m}$, and the average undercut height was $\mathrm{H}=6.5 \mathrm{~m}$ so that $\mathrm{L} / \mathrm{H}=$ 0.38 . The depth of plug above the brow was $3.1 \mathrm{~m}$, giving $\mathrm{d} / \mathrm{H}=0.48$. The performance of this filling strategy is evaluated using the proposed design procedure, with results tabulated in Table 3 and shown graphically in Figure 6. Again, detailed geometry was used to assess the relevant heights and times during the filling process, and cohesions were interpolated based on the results presented in Figure 4.

The relatively rapid strength development for this stope's CPB was clearly important to the success of this continuous pour. With reference to the field results presented in Figure 2, Cage 3 near the plug's base indicates zero effective stress up until backfilling reaches the top of brow (33 hours) yet the analysis indicates the plug has already gained significant strength (28

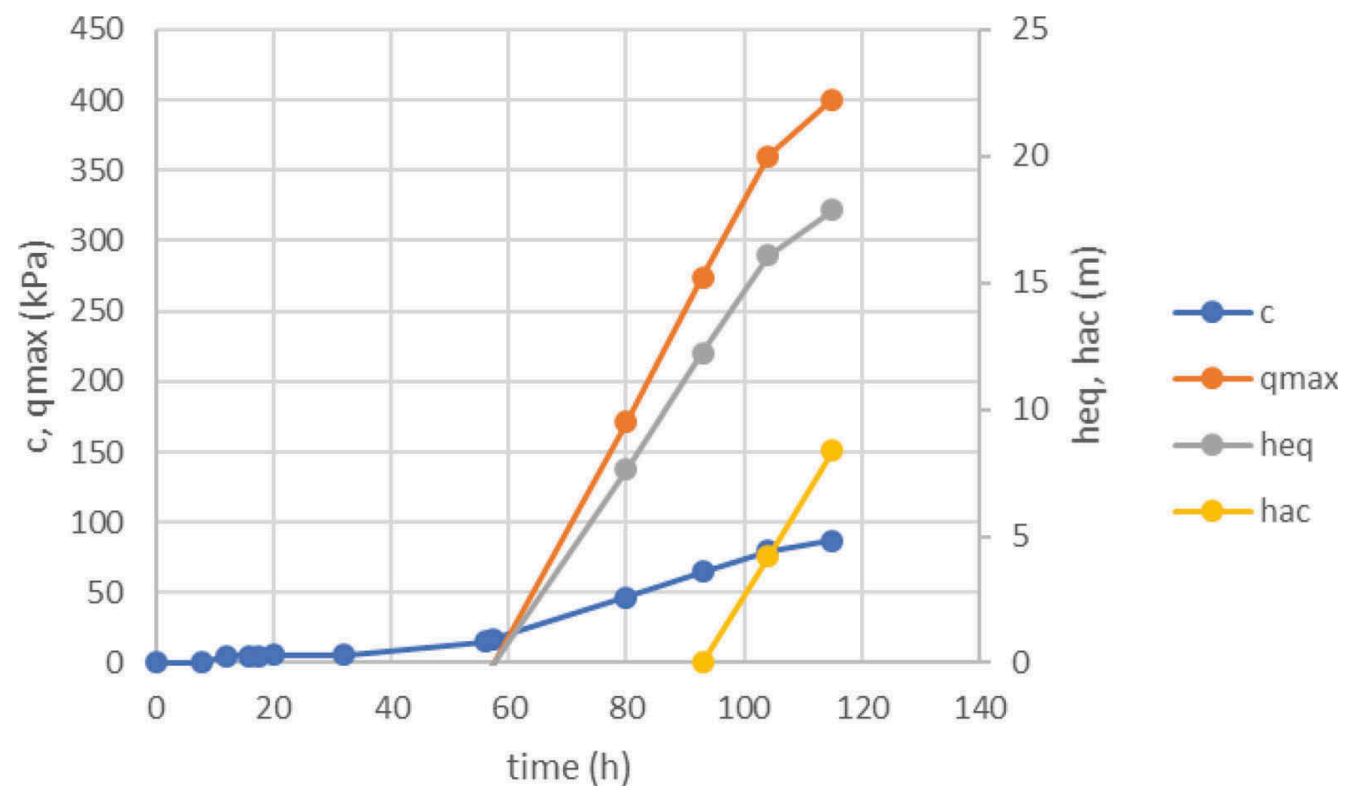

Figure 5. Actual performance of 715 stope (with plug cure period). 
Table 2. Key backfill times and plug capacities for 715 stope (based on actual backfilling history).

\begin{tabular}{|c|c|c|c|c|c|c|c|}
\hline Note & $\begin{array}{l}\text { Pour } \\
\text { time (h) }\end{array}$ & $\begin{array}{l}\text { Fill el. above } \\
\text { floor }(\mathrm{m})\end{array}$ & $\begin{array}{l}\text { Cure } \\
\text { time (h) }\end{array}$ & $\begin{array}{l}\text { Backfill } \\
\text { c (kPa, } \\
\text { Figure 4) }\end{array}$ & $\begin{array}{l}\mathrm{q}_{\max }(\mathrm{kPa}, \\
\text { Eq. 1) }\end{array}$ & $\begin{array}{l}\mathrm{h}_{\mathrm{eq}}(\mathrm{m}, \\
\text { Eq. 2) }\end{array}$ & $\begin{array}{l}\text { Fill el. } \\
\text { above } \\
\text { H (m) }\end{array}$ \\
\hline start pour 1 & 0 & 0 & $\mathrm{n} / \mathrm{a}$ & $\mathrm{n} / \mathrm{a}$ & $\mathrm{n} / \mathrm{a}$ & $\mathrm{n} / \mathrm{a}$ & $\mathrm{n} / \mathrm{a}$ \\
\hline mid-baricade & $8\left(t_{r e f}\right)$ & 2.2 & 0 & 0 & $\mathrm{n} / \mathrm{a}$ & $\mathrm{n} / \mathrm{a}$ & $\mathrm{n} / \mathrm{a}$ \\
\hline initial plugset & 12 & 3.3 & 4 & 5 & $\mathrm{n} / \mathrm{a}$ & $\mathrm{n} / \mathrm{a}$ & $\mathrm{n} / \mathrm{a}$ \\
\hline top-barricade & 16 & 4.5 & 8 & 5.2 & $\mathrm{n} / \mathrm{a}$ & $\mathrm{n} / \mathrm{a}$ & $\mathrm{n} / \mathrm{a}$ \\
\hline fill undercut & 17.5 & 5.0 & 9.5 & 5.3 & $\mathrm{n} / \mathrm{a}$ & $\mathrm{n} / \mathrm{a}$ & $\mathrm{n} / \mathrm{a}$ \\
\hline end pour 1 & 20 & 6.6 & 12 & 5.4 & $\mathrm{n} / \mathrm{a}$ & $\mathrm{n} / \mathrm{a}$ & $\mathrm{n} / \mathrm{a}$ \\
\hline $24 \mathrm{~h}$ cure & 32 & 6.6 & 24 & 6 & $\mathrm{n} / \mathrm{a}$ & $\mathrm{n} / \mathrm{a}$ & $\mathrm{n} / \mathrm{a}$ \\
\hline $48 \mathrm{~h}$ cure & 56 & 6.6 & 48 & 15 & $\mathrm{n} / \mathrm{a}$ & $\mathrm{n} / \mathrm{a}$ & $\mathrm{n} / \mathrm{a}$ \\
\hline self support & 57.5 & 6.6 & 49.5 & 17 & 0 & 0 & 0 \\
\hline $72 \mathrm{~h}$ cure & 80 & 6.6 & 72 & 47 & 171 & 7.6 & 0 \\
\hline start pour 2 & 93 & 6.6 & 85 & 65 & 274 & 12.2 & 0 \\
\hline $96 \mathrm{~h}$ cure & 104 & 10.8 & 96 & 80 & 360 & 16.1 & 4.2 \\
\hline end of filling & 115 & 15.0 & 107 & 87 & 400 & 17.9 & 8.4 \\
\hline $168 \mathrm{~h}$ cure & 176 & & 168 & 125 & & & \\
\hline
\end{tabular}

Table 3. Key backfill times and plug capacities for 685 stope (based on actual continuous pour).

\begin{tabular}{|c|c|c|c|c|c|c|c|}
\hline Note & $\begin{array}{l}\text { Pour } \\
\text { time }(\mathrm{h})\end{array}$ & $\begin{array}{l}\text { Fill el. wrt bar. } \\
\text { base (m) }\end{array}$ & $\begin{array}{l}\text { Cure } \\
\text { time (h) }\end{array}$ & $\begin{array}{l}\text { Backfill } \\
\text { c (kPa, } \\
\text { Figure 4) }\end{array}$ & $\begin{array}{l}\mathrm{q}_{\max } \\
(\mathrm{kPa}, \\
\text { Eq. 1) }\end{array}$ & $\begin{array}{l}\mathrm{h}_{\mathrm{eq}} \\
\text { (m, Eq. 2) }\end{array}$ & $\begin{array}{l}\text { Fill el. above } \\
\text { plug }(\mathrm{m})\end{array}$ \\
\hline start & 0 & 0 & $\mathrm{n} / \mathrm{a}$ & $\mathrm{n} / \mathrm{a}$ & $\mathrm{n} / \mathrm{a}$ & $\mathrm{n} / \mathrm{a}$ & $\mathrm{n} / \mathrm{a}$ \\
\hline mid-baricade & $9\left(t_{r e f}\right)$ & 2.8 & 0 & 0 & $\mathrm{n} / \mathrm{a}$ & $\mathrm{n} / \mathrm{a}$ & $\mathrm{n} / \mathrm{a}$ \\
\hline initial plugset & 13 & 3.6 & 4 & 10 & $\mathrm{n} / \mathrm{a}$ & $\mathrm{n} / \mathrm{a}$ & $\mathrm{n} / \mathrm{a}$ \\
\hline $\begin{array}{l}\text { top-barricade \& } \\
12 \text { h cure }\end{array}$ & 21 & 5.2 & 12 & 24 & $\mathrm{n} / \mathrm{a}$ & $\mathrm{n} / \mathrm{a}$ & $\mathrm{n} / \mathrm{a}$ \\
\hline fill undercut & 27 & 6.5 & 18 & 26 & 40.5 & 1.9 & $\mathrm{n} / \mathrm{a}$ \\
\hline $\begin{array}{l}\text { top of brow } \& \\
24 \text { h cure }\end{array}$ & 33 & 7.8 & 24 & 28 & 44.1 & 2.1 & $\mathrm{n} / \mathrm{a}$ \\
\hline plug filled & 39 & 9.6 & 30 & 31 & 56.3 & 2.6 & 0 \\
\hline $48 \mathrm{~h}$ cure & 57 & 13.5 & 48 & 40 & 114 & 5.3 & 3.9 \\
\hline end of filling & 70 & 16.4 & 61 & 58 & 230 & 10.7 & 6.8 \\
\hline $72 \mathrm{~h}$ cure & 81 & & 72 & 73 & & & \\
\hline
\end{tabular}

$\mathrm{kPa}$ cohesion, enough to support $2.1 \mathrm{~m}$ main fill). By the time the plug pour is completed the refence cohesion has reached $31 \mathrm{kPa}$ and could support $5.3 \mathrm{~m}$ of main fill. During the main pour the plug cohesion continues to increase. Potentially the lowest "strength factor" occurred at about 57 hours, when the plug cohesion was $40 \mathrm{kPa}$ and could support $5.3 \mathrm{~m}$ of main fill, while the main fill was actually $3.9 \mathrm{~m}$ above the plug. At the end of filling the "strength factor" increased somewhat to $10.7 \mathrm{~m}$ of supportable fill versus $6.8 \mathrm{~m}$ actual.

In summary, analysis of the first case study showed that a continuous pour would not be possible, and indeed barricade pressure data demonstrated safe loading conditions would be exceeded if the standard plug cure strategy was exceeded. For this same stope, the analysis showed that the extra cure period afforded by the time delay to main pour was sufficient to allow the late hydrating CPB to gain strength and so successfully support the resumed main pour. The second case study shows that the back analyzed strength gain with time was sufficient to support a continuous pour, although possibly just minimally at 57 hours into the pour. 


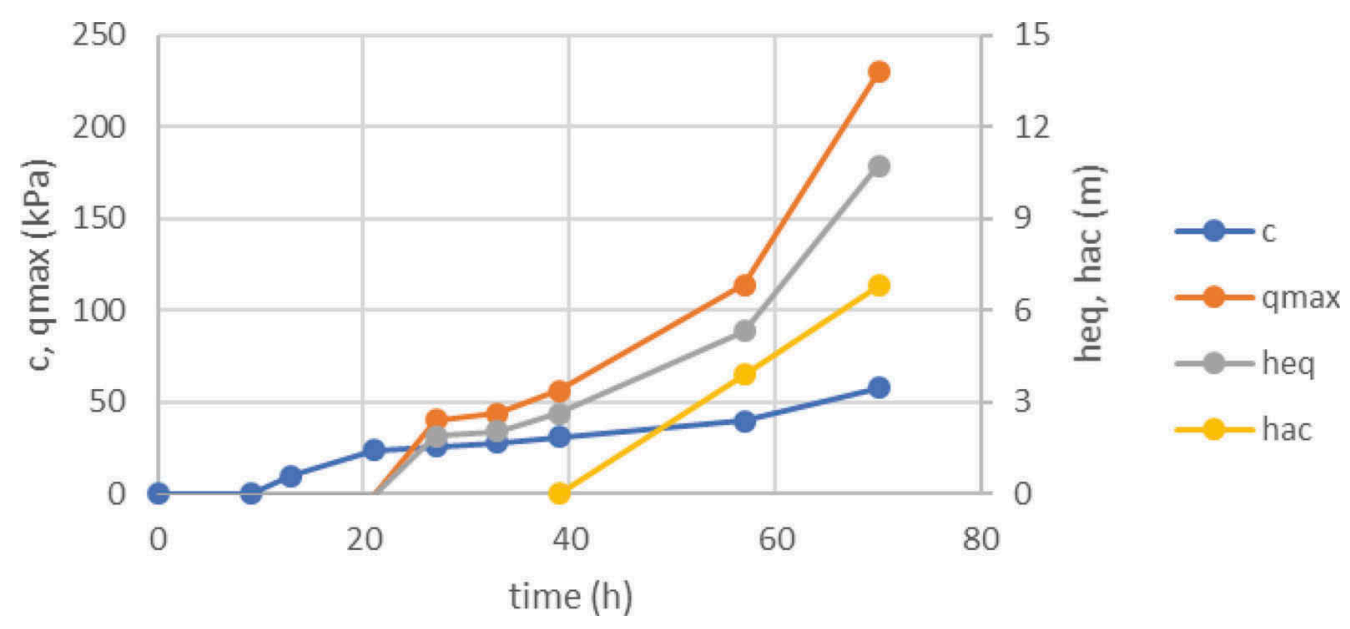

Figure 6. Actual performance of 685 stope (continuous pour).

\section{DESIGN FOR EFFECTIVE STRESS CASES}

Not all the field trials previously studied showed prolonged periods of zero effective stress. Thompson et al. (2011) show field results from Williams mine where the initial pour starts to develop effective stress before the backfill reaches the brow. Indeed, when the analysis approach presented here is applied to that case study, an unstable plug is predicted whereas the field trial resulted in a successful continuous pour. It is very likely the conservative assumption of cohesion only (Williams cohesion development is also shown in Figure 4) is not appropriate for such backfilling situations. However, attempting a full effective stress analysis is a comparatively non-trivial task. The effective stress analyses demonstrated by Helinski et al. (2010), Witteman and Simms (2010), Veenstra et al. (2011), El Mkadmi et al. (2013), Doherty et al. (2015), Shahsavari and Grabinsky (2015), and Cui and Fall (2017), demonstrate that numerical analysis techniques are well developed to simulate these situations, however the time and effort to obtain the input parameters required for these simulations is likely to be prohibitively expensive for many mines.

\section{CONCLUSION AND FUTURE WORK}

A method has been proposed to define plug strength requirements appropriate for typical plug pour, plug cure and main pour backfilling strategies. This paper has not attempted to define an adequate Factor of Safety (FS), which should include site specific factors such as expected variability of the strength properties of as-placed material. Use of instrumentation is recommended to verify barricades remain in a safe pressure range during backfilling. Indeed, many operating mines with CPB systems do not use backfill instrumentation and likely do not know how quickly effective stresses develop in their backfill plugs. These operations should implement simplified field instrumentation programs to determine their drainage conditions. Even if drainage is not very substantial (i.e., effective stresses are low or are not consistently achieved) the comparatively conservative design approach recommended here offers a good first step rational analysis approach, as compared to empirical design methods.

Mines that find their plugs consistently and reliably achieve early effective stress development can still use the recommended design procedures, realizing that they will be conservative. If the design results constrain backfill design unnecessarily, then the next step is full effective stress analysis but this step must be undertaken recognizing the significant resource 
requirements associated with determining a much wider range of material parameters, and with the additional numerical analyses.

The industry standard UCS testing is not appropriate for determining cohesion, because the obtained UCS is a function of friction as well as cohesion. The test method suggested by Veenstra (2013) is a viable alternative, but new test methods should be explored to determine if faster and easier techniques can also be used.

Mines that are currently production-limited due to stope cycle time are the most likely to realize significant benefits from implementing the above approach to investigate the feasibility of continuously backfilling using rationally designed backfills. It is our future intention to back-analyze existing continuous pour data from other mines to further calibrate this method. Any mines seeking to increase backfilling efficiency through accelerating backfilling should proceed with great caution and utilize instrumentation to verify safe barricade pressure conditions are maintained. The entire backfill community would benefit greatly if these mines collect and report data in a systematic way, so that additional mines might also undertake these recommended procedures.

\section{ACKNOWLEDGEMENTS}

This work relies heavily on the research program Geomechanical Design of Cemented Paste Backfill Systems carried out between 2007-2013 (Phase I) and 2017-2019 (Phase II), jointly sponsored by the Natural Science and Engineering Research Council Canada (NSERC) and the parent companies and personnel from Williams, Kidd, and Cayeli mines (Barrick, Xstrata, and Inmet respectively at the time of the field studies). While the research involved many graduate students and research personnel, this work has made particular use of testing results by Ryan Veenstra. The three-dimensional Flac numerical modeling was carried out by Jeff Oke while at Mine Design Engineering (MDEng), Kinston, Ontario.

\section{BIBLIOGRAPHY}

Been, K., Brown, E. T., \& Hepworth, N. 2002. Liquefaction potential of paste fill at Neves Corvo mine, Portugal. Mining Technology, 111(1), 47-58.

Cui, L. and Fall, M., 2017. Multiphysics modeling of arching effects in fill mass. Computers and Geotechnics, 83, pp. 114-131.

Doherty, J.P., Hasan, A., Suazo, G.H. and Fourie, A., 2015. Investigation of some controllable factors that impact the stress state in cemented paste backfill. Canadian Geotechnical Journal, 52(12), pp. 1901-1912.

El Mkadmi, N., Aubertin, M. and Li, L., 2013. Effect of drainage and sequential filling on the behavior of backfill in mine stopes. Canadian Geotechnical Journal, 51(1), pp. 1-15.

Grabinsky, M.W., Cheung, D., Bentz, E., Thompson, B.D., and Bawden, W.F., 2014. Advanced structural analysis of reinforced shotcrete barricades. In 11th International Symposium on Mining with Backfill, Australian Center for Geomechanics

Grice, A.G., 1998. Stability of hydraulic backfill barricades. In Proceedings of the 6th International Symposium on Mining with Backfill, AusIMM, pp. 117-120.

Grice, A.G., 2001. Recent minefill developments in Australia. In Proceedings 7th International Symposium on Mining with Backfill, SMW (Seattle - canceled), pp. 351-357.

Helinski, M., Fahey, M. and Fourie, A., 2010. Behavior of cemented paste backfill in two mine stopes: measurements and modeling. Journal of geotechnical and geoenvironmental engineering, 137(2), pp. $171-182$.

Henderson, A., Revell, M.B., Landriault, D. and Coxon, J., 2005. Chapter 6: Paste Fill. In Potvin, Y., Thomas, E. and Fourie, A. (eds) Handbook on Mine Fill. Australian Center for Geomechanics. ISBN 0-9756756-2-1.

le Roux, K., Bawden, W.F. \& Grabinsky, M.W. 2005. Field Properties of Cemented Paste Backfill at the Golden Giant Mine, Institution of Mining and Metallurgy. Section A: Mining Technology, 114(2), pp.65-80

Li, J., Ferreira, J.V., and Le Lievre, T., 2014. Transition from discontinuous to continuous paste filling at Cannington Mine. In 11th International Symposium on Mining with Backfill, Australian Center for Geomechanics. 
Mangan, S., 2001. Coroner critical of Normandy over Bronzewing deaths. MiningNews.net, 2 August 2001. (www.miningnews.net/archive/news/1192079/coroner-critical-normandy-bronzewing-deaths, accessed 201905 15).

Oke, J., Thompson, B. D., Bawden, W. F., Lausch, P., \& Grabinsky, M. W. 2018. Backfill Barricade Design: Practical Experiences and Recommendations. In 52nd US Rock Mechanics/Geomechanics Symposium. American Rock Mechanics Association.

Revell, M.B. and Sainsbury, D.P., 2007. Paste bulkhead failures. In 9th International Symposium on Mining with Backfill, Montreal, Paper, 10 p., Canadian Institute of Mining, Montreal: Proceedings on CD-ROM.

Shahsavari, M. and Grabinsky, M., 2015, September. Mine backfill porewater pressure dissipation: numerical predictions and field measurements. In Proceedings of the 68th Canadian Geotechnical Conference, Quebec City, QC, Canada (pp. 20-23).

Shahsavari, M., Moghaddam, R., \& Grabinsky, M. 2014. Liquefaction screening assessment for as-placed cemented paste backfill. In Proceedings of the Canadian Geotechnical Conference GeoRegina 2014. Canadian Geotechnical Society.

Thompson, B.D., Grabnsky, M.W., and Bawden, W.F., 2011. In situ monitoring of cemented paste backfill pressure to increase backfilling efficiency. CIM Journal, 2(4):199-209.

Thompson, B.D., Bawden, W.F., and Grabinsky, M.W. 2012. In-situ measurements of cemented paste backfill at the Cayeli Mine. Canadian Geotechnical Journal, 49(7):755-772.

Torlach, J.M., 2000. Potential hazards associated with minefill. Safety Bulletin No. 55, Mining Operations Division, Department of Minerals and Energy, East Perth WA.

Veenstra, R.L., Bawden, W.F., Grabinsky, M.W. and Thompson, B.D., 2011. An approach to stope scale numerical modelling of early age cemented paste backfill. In 45th US Rock Mechanics/Geomechanics Symposium. American Rock Mechanics Association.

Veenstra, R.L., 2013. A design procedure for determining the in situ stresses of early age cemented paste backfill. PhD Thesis, University of Toronto. Institutional electronic repository: https://tspace.library. utoronto.ca/handle/1807/36027

Witteman, M. and Simms, P., 2010. Hydraulic response in cemented paste backfill during and after hydration. In Proceedings of the Thirteenth International Seminar on Paste and Thickened Tailings, pp. 199-207. Australian Centre for Geomechanics.

Yumlu, M. and Guresci, M. 2007. Paste backfill bulkhead failures and pressure monitoring at Cayeli mine. CIM Bulletin, vol. 100, pp. 1001-1010. 